\title{
Potential exposure and treatment efficiency of nanoparticles in water supplies based
} on wastewater reclamation

\author{
Kirkegaard, Peter; Hansen, Steffen Foss; Rygaard, Martin
}

\section{Published in:}

Environmental Science: Nano

Link to article, DOI:

10.1039/C4EN00192C

Publication date:

2015

Document Version

Publisher's PDF, also known as Version of record

Link back to DTU Orbit

Citation (APA):

Kirkegaard, P., Hansen, S. F., \& Rygaard, M. (2015). Potential exposure and treatment efficiency of nanoparticles in water supplies based on wastewater reclamation. Environmental Science: Nano, 2, 191-202. https://doi.org/10.1039/C4EN00192C

\section{General rights}

Copyright and moral rights for the publications made accessible in the public portal are retained by the authors and/or other copyright owners and it is a condition of accessing publications that users recognise and abide by the legal requirements associated with these rights.

- Users may download and print one copy of any publication from the public portal for the purpose of private study or research.

- You may not further distribute the material or use it for any profit-making activity or commercial gain

- You may freely distribute the URL identifying the publication in the public portal 


\section{Environmental Science Nano}

CrossMark $\leftarrow$ click for updates

Cite this: DOI: $10.1039 / \mathrm{c} 4 \mathrm{en} 00192 \mathrm{c}$

Received 22nd November 2014 Accepted 26th January 2015

DOI: $10.1039 / c 4 e n 00192 c$

rsc.li/es-nano

\section{Potential exposure and treatment efficiency of nanoparticles in water supplies based on wastewater reclamation}

\author{
Peter Kirkegaard, Steffen Foss Hansen* and Martin Rygaard
}

\begin{abstract}
Water scarcity brings an increased focus on wastewater reclamation for drinking water supply. Meanwhile, the production volume of nanoparticles (NPs) is rapidly increasing, but to date there has been little attention given to the fate of NPs in water systems based on wastewater reclamation. We have investigated the possible concentrations of silver $(\mathrm{Ag})$, titanium dioxide $\left(\mathrm{TiO}_{2}\right)$, and zinc oxide $(\mathrm{ZnO})$ nanoparticles in tap water for water supplies based on reclaimed wastewater. Tap water concentrations of the NPs were assessed by mass flow analyses of two typical wastewater reclamation concepts: 1) advanced membrane treatment and 2) bank infiltration, similar to systems established in Orange County, CA, USA and Berlin, Germany. The mass flow analyses are based on a literature review of known wastewater concentrations of NPs and removal efficiencies for the implemented treatment stages in two case systems. Few studies are available on the removal efficiencies of NPs by advanced water treatment processes with a majority of the identified studies focusing on removal efficiencies in wastewater treatment plants and fate in surface waters. The NP removal efficiency of several treatment processes is unknown at this stage. We found the worst case removal efficiencies for the two cases to be $97-99.97 \%$ for Ag-NPs, $91-99.2 \%$ for $\mathrm{TiO}_{2}-\mathrm{NPs}$, and $92-93 \%$ for $\mathrm{ZnO}-\mathrm{NPs}$. The corresponding worst case concentrations in tap water for the advanced membrane treatment were $0.04 \mu \mathrm{g} \mathrm{L}^{-1}(\mathrm{Ag}), 147 \mu \mathrm{g} \mathrm{L}^{-1}\left(\mathrm{TiO}_{2}\right)$, and $0.28 \mu \mathrm{g} \mathrm{L}^{-1}(\mathrm{ZnO})$. The concentration of $\mathrm{ZnO}-\mathrm{NPs}$ also includes zinc ions, thus the concentration of $\mathrm{ZnO}-\mathrm{NPs}$ is likely to be lower than that indicated here. The worst case removal by the wastewater reclamation bank infiltration system was predicted to lead to tap water concentrations of up to $3.3 \mu \mathrm{g} \mathrm{L}^{-1}(\mathrm{Ag}), 13 \mu \mathrm{g} \mathrm{L}^{-1}\left(\mathrm{TiO}_{2}\right)$, and $0.25 \mu \mathrm{g} \mathrm{L}^{-1}(\mathrm{ZnO})$. Overall, it is found that the primary removal mechanisms of NPs are aggregation, sedimentation, coagulation, and biosorption; this supports observations that conventional biological treatment processes are likely to be effective barriers against NPs. Advanced treatment methods such as microfiltration and ultrafiltration can exhibit very low removal of $\mathrm{ZnO}-\mathrm{NPs}$ or zinc ions due to dissolution of $\mathrm{ZnO}-\mathrm{NPs}$. There are marked knowledge gaps, and further research on NP fate in water treatment is encouraged.
\end{abstract}

\section{Nano impact}

In this article we present the first ever evaluation of the removal of nanoparticles in wastewater by different water treatment processes in order to estimate the concentrations of NPs in reclaimed wastewater for potable reuse. Based on the mass flow analysis of two specific water reclamation cases (i.e. Orange County and Berlin) and a literature review, we found that silver ( $\mathrm{Ag}$ ), titanium dioxide ( $\mathrm{TiO}_{2}$ ), and zinc oxide ( $\mathrm{ZnO}$ ) nanoparticles may occur in concentrations up to $3 \mu \mathrm{g} \mathrm{L}^{-1}(\mathrm{Ag}), 147 \mu \mathrm{g} \mathrm{L}^{-1}\left(\mathrm{TiO}_{2}\right)$, and $0.3 \mu \mathrm{g} \mathrm{\textrm {L } ^ { - 1 }}(\mathrm{ZnO})$. Critical research needs evolve around understanding the fate of nanoparticles treated by reverse osmosis, UV and disinfection processes and understanding which kinds of nanoparticles in various types of products end up in our water supply.

\section{Introduction}

Engineered nanoparticles (NPs) are used to an ever increasing extent, e.g. in consumer products, but we know very little about how they are used and where they end up. According

Department of Environmental Engineering, Technical University of Denmark, Denmark. E-mail: sfh@env.dtu.dk to The Nanodatabase (www.nanodb.dk), which is a database maintained by the Danish Ecological Council, the Danish Consumer Council and the Department of Environmental Engineering at the Technical University of Denmark, more than 1200 products claimed to be based on nanotechnology or containing nanomaterials are now available to European consumers on-line. $52 \%$ of these products entail nanoparticles suspended in liquids, e.g. personal care products 
such as cosmetics, and only about $16 \%$ and $7 \%$ have surface bound NPs or NPs suspended in solids; hence it is reasonable to assume that most of these compounds will ultimately end up in our wastewater treatment systems (Fig. 1).

Treated wastewater ends up in recipients such as rivers, lakes, and oceans, where it may, planned or unplanned (de facto), become an indirect source of drinking water supplies. $^{1,2}$ Although few large scale reclamation plants for potable reuse are operational, it has been suggested that direct potable reuse can play a much larger role in future solutions to water scarcity. ${ }^{3}$ With the occurrence of nanoparticles in wastewater it is therefore relevant to investigate their potential presence and effective treatment in drinking water.

In this paper, we estimate the concentrations of silver (Ag), titanium dioxide $\left(\mathrm{TiO}_{2}\right)$, and zinc oxide ( $\left.\mathrm{ZnO}\right)$ NPs that can be expected to end up in the water supply as a consequence of wastewater reclamation. NanoAg, nanoTiO ${ }_{2}$ and nanoZnO were chosen as they are the most commonly used

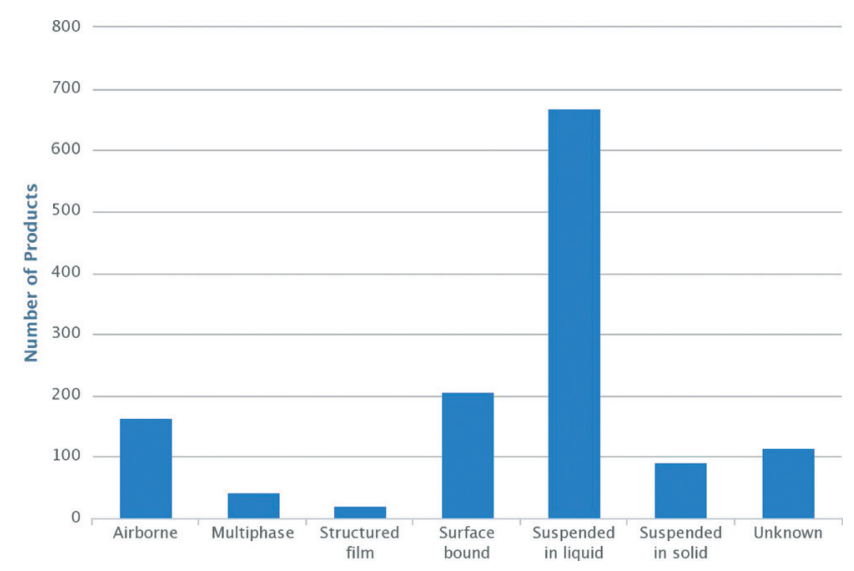

Fig. 1 Number of products with registered location of nanoparticles (nanodb.dk).

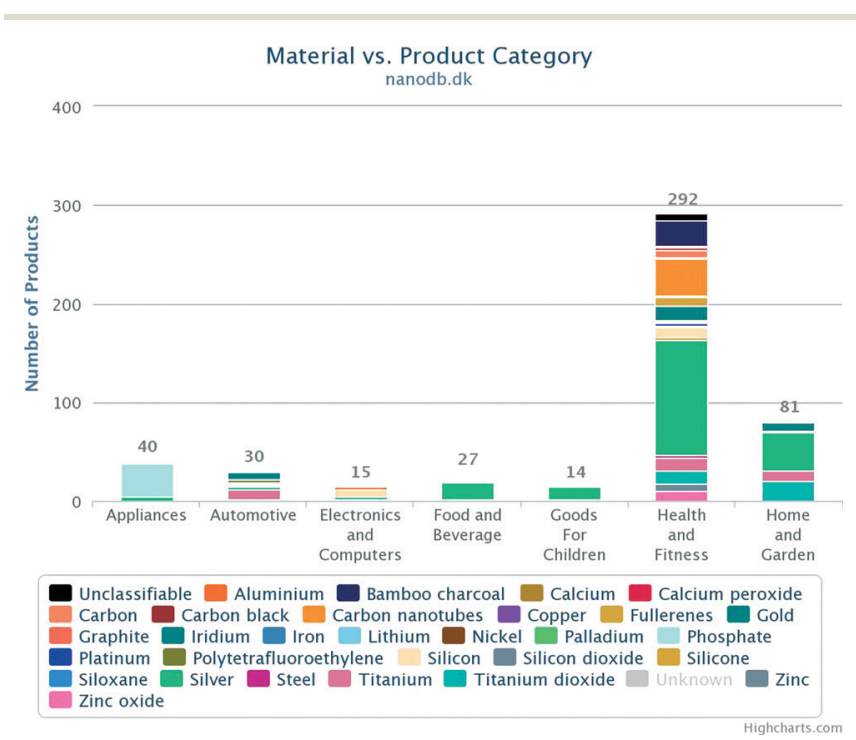

Fig. 2 Number of registered nanoparticles grouped by product category (nanodb.dk).
NPs in consumer products (Fig. 2). ${ }^{4,5}$ These three NPs are often suspended in liquids when used in consumer products and hence can be expected to end up in wastewater. Other nanoparticles which are produced in large quantities annually are carbon black and silicon dioxide. ${ }^{6}$ However, carbon black nanoparticles are predominantly used in products (e.g. tires) which are disposed at landfills, ${ }^{7,8}$ while silicon dioxide is predominately used in food products and is not viewed as a health hazard even in a concentration of $1500 \mathrm{mg} \mathrm{L}^{-1}$. Therefore, these nanoparticles are not assessed in this study.

\section{Method}

The exposure and fate of nanoparticles in water treatment were investigated by mass flow analysis of two typical wastewater reclamation concepts based on a review of current knowledge on nanoparticle fate in water treatment systems. A literature review was conducted to find current knowledge on typical NP concentrations in wastewater, and their fate and transformation in wastewater treatment processes, advanced wastewater treatment, surface water, drinking water treatment, and natural filtration through a soil column.

\subsection{Two typical concepts for wastewater reclamation}

We estimated the potential NP concentration in drinking water for two existing water reuse systems in Orange County, California, USA ${ }^{3}$ and Berlin. ${ }^{1}$ Orange County is situated in a water-scarce region and relies partly on the importation of water from outside the area. The Municipal Water District of Orange County (MWDOC) base its water supply on $62 \%$ groundwater, $34 \%$ imported water, and $4 \%$ surface water. ${ }^{9}$ Since the 1970's, groundwater has been replenished by reclaimed wastewater. The wastewater reclamation system of Orange County (Fig. 3A) consists of a conventional wastewater treatment plant (plant no. 1) which discharges its effluent to the Advanced Water Treatment Facility (AWTF) that is part of the Groundwater Replenishment System (GWRS) for the Orange County area. The Advanced Water Treatment Facility employs treatment methods such as disinfection, UV, microfiltration, and reverse osmosis. The effluent from the Advanced Water Treatment Facility is suitable for drinking and is subsequently delivered to the Santa Ana groundwater basin. After abstraction, the groundwater is disinfected before distribution to public water supply. ${ }^{10}$

Berlin's water supply is less technology-intensive than Orange County's. In Berlin, local groundwater is abstracted from local aquifers and then treated by aeration and sand filtration before distribution to the city (Fig. 3B). The aquifers are recharged with water from the local rivers and lakes. ${ }^{11}$ It is a "de facto" reclamation scheme because the same rivers and lakes also receive the effluent from local conventional wastewater treatment plants. ${ }^{12}$ Because of the recognized link between wastewater effluents and drinking water, ${ }^{13,14}$ Berlin has high awareness of keeping the state of the lakes and rivers healthy. Groundwater abstraction mainly occurs in soil layers dominated by sand and gravel in a depth of 30 to $50 \mathrm{~m}$ 
A) Orange County

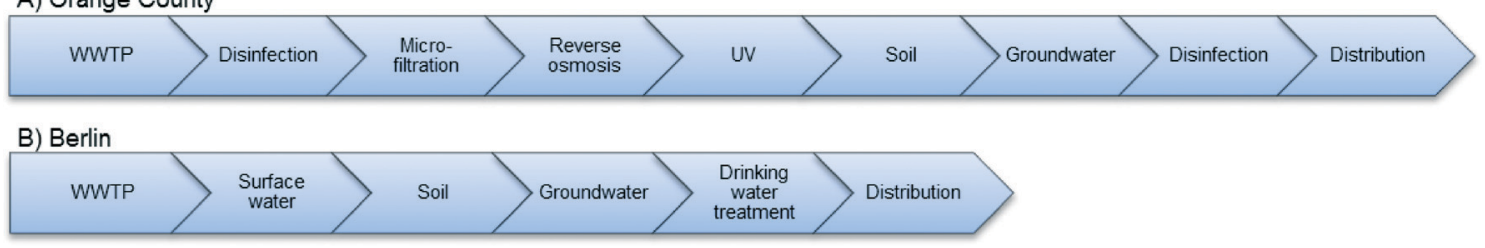

Fig. 3 Conceptual diagram of the wastewater reclamation systems in (A) Orange County and (B) Berlin. ${ }^{1,2,54}$

below the surface. ${ }^{12}$ In the central area of Berlin, the sewage system is combined, e.g. rain water and wastewater are collected by the same pipes. In the event of an overflow in this system, some of the sewage water is discharged to the rivers untreated because of WWTP capacity overload. In the aftermath of such an event, increased concentrations of usually well removed contaminants have been detected in the rivers, while contaminants which are usually difficult to remove are found in lower concentrations in the rivers due to dilution. ${ }^{15}$

\subsection{Mass flow analysis}

The removal efficiency by the two systems in Berlin and Orange County was assessed using mass flow analysis following the basic principles presented by Brunner. ${ }^{16}$ The considered mass flow analysis is a simple model which is based on the removal efficiencies identified for each of the treatment processes used in the investigated wastewater reclamation systems. The setup of the model shows that the nanoparticles that escaped from the previous treatment step are removed by the identified removal efficiency of the proceeding treatment process. Therefore, the model does not take the concentration dependency of the identified removal processes into account, e.g. it is well-known that removal by aggregation is concentration dependent.

In order to properly evaluate the NP fate in the reclamation concepts, the removal efficiencies of the three NPs by the treatment stages are assessed in two scenarios representing the worst and best case evaluations of the assumed removal efficiencies. The lowest removal efficiency in each range is assumed to represent the worst case removal scenario, while the corresponding highest removal efficiency is used for the best case removal scenario. When only a single value for the NP removal efficiency by a given treatment stage has been identified, this single value is assumed to be the removal efficiency in both the minimum and maximum removal scenarios. When there is no documentation for the removal efficiency of a given NP by a given treatment stage, the minimum removal is assumed to be $0 \%$ and the maximum removal to be $100 \%$.

\section{Results}

\subsection{NP concentrations in wastewater}

The estimation of the potential end concentration of NPs in drinking water starts with the estimation of the concentration in the wastewater influent. Gottschalk et al. ${ }^{17}$ modelled the concentrations of $\mathrm{Ag}-\mathrm{NPs}, \mathrm{TiO}_{2}$ - $\mathrm{NPs}$, and $\mathrm{ZnO}-\mathrm{NPs}$ in the WWTP effluent for US, EU, and Switzerland. Tiede et al. ${ }^{8}$ used different forms of modeling to calculate the concentrations of $\mathrm{TiO}_{2}$-NPs and Ag-NPs in the WWTP effluent which again are based on the use, product concentration, and fate estimations reported by Boxall et al.,$^{18}$ Mueller \& Nowack, ${ }^{19}$ and Gottschalk et al. ${ }^{17}$ From their results we assumed WWTP influent concentrations of $107.2 \mu \mathrm{g} \mathrm{L} \mathrm{L}^{-1}$ for Ag-NPs, $1636.4 \mu \mathrm{g} \mathrm{\textrm {L } ^ { - 1 }}$ for $\mathrm{TiO}_{2}$-NPs, and $3.6 \mu \mathrm{g} \mathrm{L}^{-1}$ for $\mathrm{ZnO}-\mathrm{NPs}$.

\subsection{Fate of NPs in treatment processes}

When it comes to understanding and mapping what happens to the NPs in the treatment processes, the specific fate and transformation process in the sewer, the WWTP, microfiltration, etc. is of vital importance. Out of the 71 studies identified for the period 2008-2013 (Fig. 4), wastewater treatment plants (27) and surface water (17) have received the most attention. Then come microfiltration (7), drinking water treatment plants (7), ultrafiltration (6), and soil and groundwater (6). Sewers, reverse osmosis, UV and disinfection have been covered by $0-1$ study each.

The estimated removal efficiencies of $\mathrm{Ag}-\mathrm{NPs}, \mathrm{TiO}_{2}$-NPs, and ZnO-NPs by each treatment stage identified in the literature are presented in Table 1 and will be discussed in the following paragraphs in the light of Orange County and Berlin.

3.2.1 Sewer. Kaegi et al. ${ }^{20}$ observed that due to the much larger surface areas, the Ag-NPs will tend to attach to the larger surface of suspended solids rather than biofilms in sewage pipes. Therefore, it is likely that about $0 \%$ of Ag-NPs will be retained in the sewers although a portion of the Ag-NPs might have become sulfidized upon arrival at the WWTPs. No identified studies have investigated the fate of $\mathrm{TiO}_{2}$-NPs and ZnO-NPs in the sewers.

3.2.2 WWTP. The removal efficiency of Ag-NPs by WWTPs has been found to be in the range of $39-99.9 \%$ under varying conditions related to NP surface coating and concentration of TSS. ${ }^{17,19-24}$ However, peak loadings of Ag-NPs to WWTPs may cause a large fraction of the Ag-NPs to end up in the effluent due to constraints in sorption kinetics and capacity of the biosolids to which the Ag-NPs could be attached/absorbed. ${ }^{22}$ Musee et al. ${ }^{25}$ found that Ag-NPs have strong attraction to the sludge and low solubility regardless of the $\mathrm{pH}$ level of the wastewater. In general, activated sludge (e.g. heteroaggregation) is likely to be the main driver of retention of Ag-NPs. ${ }^{20-23,26,27}$

Similar to the removal efficiency of Ag-NPs, the increased concentration of TSS is likely to result in the increased 


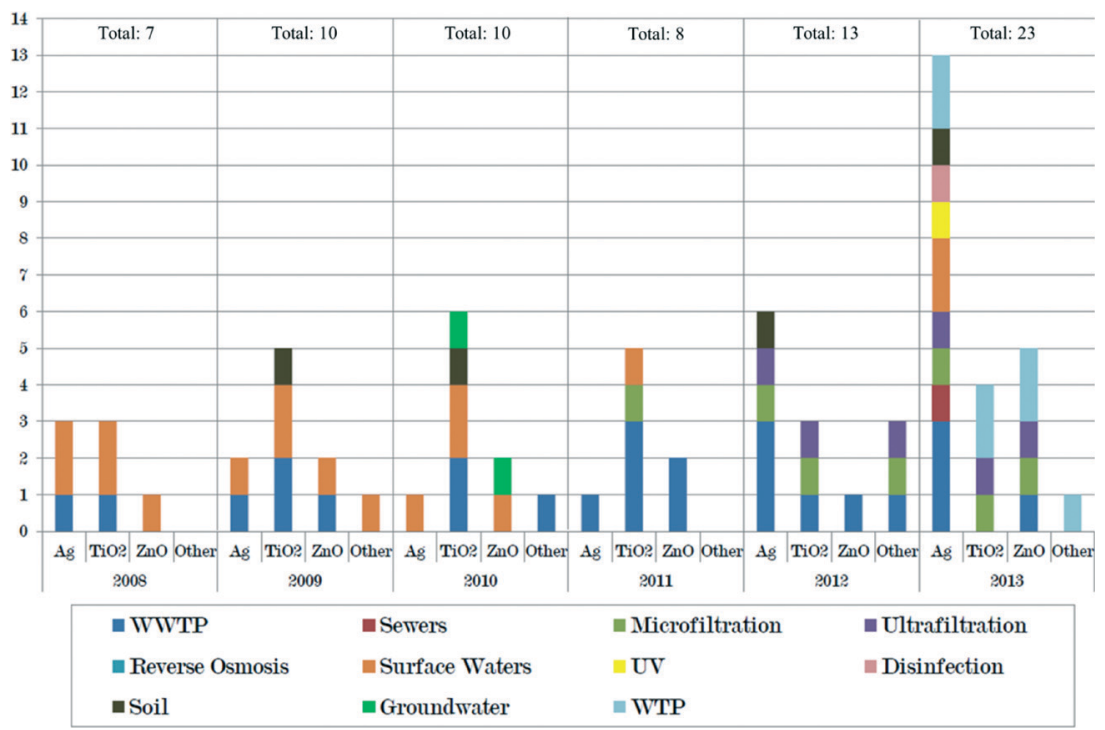

Fig. 4 Number of published studies dealing with NP fate in water treatment processes grouped by year. Retrieved from the International Council on Nano Technology ICON database and Web of Science. 'Other' refers to publications dealing with NPs apart from Ag, TiO 2 , and $\mathrm{Zn}-\mathrm{NPs}$.

removal of the influent $\mathrm{TiO}_{2}$-NPs. ${ }^{24,27}$ The removal efficiencies of $\mathrm{TiO}_{2}$-NPs at $23-97 \%$ depending on the type of surface coating and concentration of TSS have been observed. ${ }^{24,27}$ Due to the very low solubility of $\mathrm{TiO}_{2}$-NPs, the presence of ionic Ti is not expected. ${ }^{24}$ The results presented by Johnson $e t$ al. ${ }^{26}$ indicate that the primary treatment can remove about $13 \%$ and the secondary treatment (activated sludge) removes more than $88 \%$. Overall, Johnson et al. found the removal efficiency of $\mathrm{TiO}_{2}$-NPs by WWTPs to be $90 \%{ }^{26}$

Most of the ZnO-NPs are estimated to agglomerate and aggregate in WWTPs. ${ }^{28,29}$ Overall, the removal efficiency of ZnO-NPs by WWTPs is likely to be $88-100 \% .^{17,28}$

It should be noted that all three NPs are found to have a potential inhibitive effect on the microbial community in the WWTPs, at least in a short term until the microbes have adapted to the new compounds. ${ }^{21,24,25,28,30-34}$

3.2.3 Microfiltration and ultrafiltration. Micro- and ultrafiltration are key treatment stages in many wastewater reclamation schemes. ${ }^{2}$ Although microfiltration and ultrafiltration membranes are likely to retain a significantly large portion of NPs, a small fraction is still expected to break through. Abbott Chalew et al. found that $55-99 \%$ of Ag-NPs and $56-100 \%$ of $\mathrm{TiO}_{2}$-NPs are likely to be retained by microfiltration membranes and that $98-100 \%$ of $\mathrm{Ag}$-NPs and $96-100 \%$ of $\mathrm{TiO}_{2}-\mathrm{NPs}$ will be retained by ultrafiltration membranes. ${ }^{35}$ However, the expected dissolution of ZnO-NPs to zinc ions at neutral $\mathrm{pH}$ values is expected to cause a much lower removal efficiency of ZnO-NPs of $17-64 \%$ by microfiltration and $4-98 \%$ by ultrafiltration membranes, although it is unclear how large a fraction is transformed into zinc ions $^{35}$ (Table 1). Ladner et al. found that the removal efficiency of NPs by a membrane largely depends on the properties of the NPs as well as the membrane surface functionality. ${ }^{36}$ Especially, the surface charge of the nanoparticles is essential as electrostatic repulsion/attraction with the typically negatively charged membranes is an important aspect of the overall removal efficiency. Moreover, the molecular weight cut-off (MWCO) of the membrane is an important parameter, with higher MWCO providing an increased risk of break through of especially negatively charged nanoparticles. Overall, $0-10 \%$ of the negatively charged Ag-NPs and $\mathrm{TiO}_{2}$-NPs and about $100 \%$ of the positively charged $\mathrm{TiO}_{2}$-NPs were observed to be removed by microfiltration membranes (pore size of $0.1-10 \mu \mathrm{m}^{37}$ ). For ultrafiltration membranes (pore size of $1-100 \mathrm{~nm}^{37}$ ), $60-90 \%$ of the negatively charged $\mathrm{Ag}$-NPs (including $14 \%$ of $\mathrm{Ag}-\mathrm{NPs}(-)$ which were dissolved), $95-100 \%$ of $\mathrm{TiO}_{2}-\mathrm{NPs}(-)$ and about $100 \%$ of $\mathrm{TiO}_{2}-\mathrm{NPs}(+)$ were observed to be removed. ${ }^{36}$ The removal efficiencies found by Abbott Chalew et al..$^{35}$ are valid for $\mathrm{pH}=7-8$ of the solution, while the results obtained by Ladner et al..$^{36}$ are for $\mathrm{pH}=8.2-9.6$. This indicates that the $\mathrm{pH}$ of the solution also has an effect on the removal efficiency of NPs by a given membrane.

In Orange County, the water is treated by microfiltration after the disinfection stage in the Advanced Water Treatment Facility. The $\mathrm{pH}$ values of the microfiltration influent and effluent are 7.3 and 7.5, respectively. ${ }^{10}$ Therefore, we assume that the removal efficiencies obtained by Abbott Chalew et $a .^{35}$ should be applicable to the microfiltration units in the AWTF. It is noted that the removal efficiency by microfiltration/ultrafiltration membranes possibly can increase for ZnO-NPs by adjusting the $\mathrm{pH}$ to a higher level as some results indicate. ${ }^{35}$

3.2.4 Disinfection. When the effluent from the WWTP arrives at the AWTF in Orange County, the first stage of treatment is disinfection by using sodium hypochlorite. Yuan $e t$ al. found that by adding sodium hypochlorite to the water, about $95 \%$ of the Ag-NPs were removed regardless of the $\mathrm{pH}$ level of the water. ${ }^{38}$ Hydrogen peroxide and other disinfectants are also used in the AWTF, which might contribute 
Table 1 Overview of the removal efficiencies of $\mathrm{Ag}-\mathrm{NPs}, \mathrm{TiO}_{2}-\mathrm{NPs}$, and $\mathrm{ZnO}-\mathrm{NPs}$ by water treatment reported from field studies (field), laboratory experiments (lab.), and computer simulations (sim.)

\begin{tabular}{|c|c|c|c|c|c|c|c|}
\hline Stage & Reference & Comments & $\mathrm{Ag}$ & $\mathrm{TiO}_{2}$ & $\mathrm{ZnO}$ & $\begin{array}{l}\text { Type of } \\
\text { study }\end{array}$ & $\begin{array}{l}\text { Considered } \\
\text { in the mass } \\
\text { flow analysis }\end{array}$ \\
\hline Sewers & (Kaegi et al., 2013) & $\begin{array}{l}\text { The Ag-NPs are observed to be stabilized by } \\
\text { adsorption to sulfides and suspended solids. }\end{array}$ & 0 & - & - & $\begin{array}{l}\text { Lab. } \\
\text { +field }\end{array}$ & Yes \\
\hline \multirow[t]{9}{*}{$\begin{array}{l}\text { Wastewater } \\
\text { treatment plants }\end{array}$} & (Kaegi et al., 2013) & $\begin{array}{l}\text { Overall, sedimentation, aggregation and } \\
\text { adsorption are identified as the primary }\end{array}$ & 98.9-99.9 & - & - & $\begin{array}{l}\text { Lab. } \\
\text { +field }\end{array}$ & Yes \\
\hline & (Jeong et al., 2012) & mechanisms for the removal of the NPs. The & $70-90$ & - & - & Lab. & Yes \\
\hline & (L. Li et al., 2013) & increased concentration of Total Suspended & 95 & - & - & Lab. & Yes \\
\hline & (Wang et al., 2012) & $\begin{array}{l}\text { Solids (TSS) is observed to increase the } \\
\text { removal of the NPs (M. A. Kiser } \text { et al., 2010; }\end{array}$ & $\begin{array}{l}39-59 \\
84-92\end{array}$ & $65-98$ & - & Lab. & Yes \\
\hline & $\begin{array}{l}\text { (M. A. Kiser et al., 2010) } \\
\text { (Mueller and Nowack, } \\
\text { 2008) }\end{array}$ & $\begin{array}{l}\text { Wang et al., 2012). In addition, Li et al. } \\
\text { (L. Li } \text { et al., 2013) found the removal } \\
\text { efficiencies of mechanical treatment and }\end{array}$ & $\overline{81}-92^{a}$ & $\begin{array}{l}23-88 \\
81-87.6^{a}\end{array}$ & - & $\begin{array}{l}\text { Lab. } \\
\text { Sim. }\end{array}$ & $\begin{array}{l}\text { Yes } \\
\text { Yes }\end{array}$ \\
\hline & (Gottschalk et al., 2009) & biological treatment to be $35 \%$ and & $\sim 76^{a}$ & $\sim 76^{a}$ & $\sim 88^{a}$ & Sim. & Yes \\
\hline & (Gottschalk et al., 2010) & $72 \%$, respectively. & - & $\sim 86.6^{a}$ & - & Sim. & Yes \\
\hline & (Johnson et al., 2011) & & - & $\sim 89.5$ & - & Field & Yes \\
\hline & (Hou et al., 2013) & & - & - & $\sim 100$ & Lab. & Yes \\
\hline \multirow[t]{2}{*}{ Microfiltration } & $\begin{array}{l}\text { (Abbott Chalew et al., } \\
2013 \text { ) }\end{array}$ & $\begin{array}{l}\text { Abbott Chalew et al. report for } \mathrm{pH} 7-8 \text { and } \\
\text { Ladner } \text { et al. report for } \mathrm{pH} 8.2-9.6 \text {. }\end{array}$ & $55-99$ & $56-100$ & $17-64$ & Lab. & Yes \\
\hline & (Ladner et al., 2012) & & $0-10$ & $\begin{array}{l}0-10 \\
\sim 100\end{array}$ & - & Lab. & $\mathrm{No}^{b}$ \\
\hline \multirow[t]{2}{*}{ Ultrafiltration } & $\begin{array}{l}\text { (Abbott Chalew et al., } \\
\text { 2013) }\end{array}$ & $\begin{array}{l}\text { Abbott Chalew et al. report for } \mathrm{pH} 7-8 \text { and } \\
\text { Ladner } \text { et al. report for } \mathrm{pH} 8.2-9.6 \text {. }\end{array}$ & 98-100 & $96-100$ & $4-98$ & Lab. & Yes \\
\hline & (Ladner et al., 2012) & & $60-90$ & 95-100 & - & Lab. & $\mathrm{No}^{b}$ \\
\hline Reverse osmosis & N/A & $\begin{array}{l}\text { It is expected that reverse osmosis should } \\
\text { have a removal efficiency better than } \\
\text { ultrafiltration (Abbott Chalew et al., 2013; } \\
\text { Ganzleben et al., 2011); the actual removal } \\
\text { efficiency has not been investigated. }\end{array}$ & N/A & N/A & N/A & N/A & N/A \\
\hline UV & (Yuan et al., 2013) & $\begin{array}{l}\text { Oxidative dissolution was found to be the } \\
\text { dominant reaction when Ag-NPs were } \\
\text { exposed to disinfectants. In addition, the } \\
\text { level of pH, sodium nitrate, humic acid and } \\
\text { the type of disinfectant are important for } \\
\text { predicting the removal of NPs by disinfection. }\end{array}$ & $17-67^{a}$ & - & - & Lab. & Yes \\
\hline Disinfection & (Yuan et al., 2013) & & $95^{a}$ & - & - & Lab. & Yes \\
\hline \multirow[t]{5}{*}{ Surface waters } & (Gottschalk et al., 2009) & The dominant removal mechanisms in & $\sim 50$ & $\sim 99$ & $\sim 70$ & Sim. & Yes \\
\hline & (Gottschalk et al., 2010) & surface waters seem to be the low $\mathrm{pH}$ and & - & $\sim 50$ & - & Sim. & Yes \\
\hline & $\begin{array}{l}\text { (Ticiana Boncagni et al., } \\
\text { 2009) }\end{array}$ & $\begin{array}{l}\text { flow rate as well as increased flocculation, } \\
\text { sedimentation, aggregation, and electrostatic }\end{array}$ & - & $\sim 100$ & - & Lab. & Yes \\
\hline & (Zhang et al., 2008) & attraction. & - & $53-75^{a}$ & $\sim 75^{a}$ & Lab. & Yes \\
\hline & (Keller et al., 2010) & & - & $\sim 77^{a}$ & $\sim 24^{a}$ & Lab. & Yes \\
\hline \multirow[t]{3}{*}{ Soil } & (Sagee et al., 2012) & In general, the studies observed that the low & $22^{a}$ & - & - & Lab. & Yes \\
\hline & (Fang et al., 2009) & grain sizes, low concentration of humic acid, & - & $17-99.8$ & - & Lab. & Yes \\
\hline & (Solovitch et al., 2010) & $\begin{array}{l}\text { low flow conditions, low } \mathrm{pH} \text { value, and high } \\
\text { ionic strength of the soil promote electrostatic } \\
\text { attraction and mechanical straining of } \\
\text { the NPs. }\end{array}$ & - & 5-99 & - & Lab. & Yes \\
\hline Groundwater & (Keller et al., 2010) & $\begin{array}{l}\text { The increased ionic strength and } \\
\text { concentration of Total Organic Carbon (TOC) } \\
\text { promote retention of NPs. }\end{array}$ & - & $72^{a}$ & $21.5^{a}$ & Lab. & Yes \\
\hline $\begin{array}{l}\text { Water treatment } \\
\text { plants }\end{array}$ & $\begin{array}{l}\text { (Abbott Chalew et al., } \\
\text { 2013) }\end{array}$ & $\begin{array}{l}\text { Sand filtration is observed to remove } 100 \% \text { of } \\
\text { the uncoated NPs while below } 40 \% \text { of the } \\
\text { coated NPs (depending on the type and } \\
\text { surface coating) can be removed by sand } \\
\text { filters. Moreover, sand filtration seems to be } \\
\text { susceptible towards a continuous influent } \\
\text { resulting in a larger break through of the NPs } \\
\text { than in a peak flow (Z. Li } \text { et al., 2013). }\end{array}$ & $80-98$ & $92-97$ & $1-52$ & Lab. & Yes $^{c}$ \\
\hline
\end{tabular}

${ }^{a}$ The removal efficiencies are read from graphs, tables or data. ${ }^{b}$ Not considered since the microfiltration influent and effluent in the ATWF of Orange County have $\mathrm{pH}$ values of 7.3 and 7.5 (GWRS, 2013). ${ }^{c}$ The conventional water treatment simulated by Abbott Chalew et al. (Abbott Chalew et al., 2013) is based upon coagulation and the removal efficiencies are therefore not necessarily the correct removal efficiencies for the drinking water treatment plants in Berlin. 
further to the overall removal of NPs. Additionally, no studies, which investigated the corresponding removal efficiencies of $\mathrm{TiO}_{2}$-NPs and $\mathrm{ZnO}-\mathrm{NPs}$, were found.

In Orange County, the groundwater is typically disinfected prior to distribution to the consumer. $14 \%$ of the extracted groundwater is treated by ultrafiltration and reverse osmosis among others before distribution. ${ }^{39}$ However, for this mass flow analysis, these water treatment processes are disregarded at this stage due to their insignificant effect. In Anaheim, Orange County, sodium hypochlorite $(12.5 \%)$ is used as the only treatment of groundwater prior to distribution (personal communication), while the water utility in Irvine Ranch adds chloramine at about $3 \mathrm{ppm}$ in order to keep a ratio of 4.5:1 chloramine to ammonia (personal communication). The $\mathrm{pH}$ levels of the groundwater in Anaheim and Irvine Ranch are 7.9 and 8.2, respectively (personal communication). However, Yuan et al. found that changes in the $\mathrm{pH}$ level would have little effect on the removal efficiency of Ag-NPs. ${ }^{38}$ Therefore, the removal efficiency of the remaining $\mathrm{Ag}$-NPs by the treatment of groundwater is estimated to be approximately 95\%. The literature does not provide the corresponding values for $\mathrm{TiO}_{2}$-NPs and $\mathrm{ZnO}-\mathrm{NPs}$, therefore, their removal efficiencies are assumed to be $0 \%$ and $100 \%$, respectively, in the mass flow analysis.

3.2.5 Reverse osmosis. To the best of our knowledge, no studies have been published on the effectiveness of RO when it comes to the removal of NPs. Due to smaller membrane pore sizes, the removal efficiency by reverse osmosis can be expected to be better than the removal efficiencies by ultrafiltration. Studies on micropollutants have shown that molecules larger than the membrane pore size can pass through reverse osmosis membranes. It was found that the rejection rates of micropollutants by reverse osmosis could be influenced by parameters other than size exclusion, including feed water quality, fouling and membrane materials. ${ }^{40,41}$ Therefore, the potential of reverse osmosis in retaining NPs might be less than what one can expect from size exclusion alone. To account for this knowledge gap, the reverse osmosis removal rates for all three NPs were assumed to be between $0 \%$ and $100 \%$ in the mass flow analysis.

3.2.6 UV. After the reverse osmosis treatment process, the permeate water is treated by UV irradiation. At this stage, the $\mathrm{pH}$ of the water is $5.7 .^{10}$ Yuan et al. observed that at $\mathrm{pH}=5.2$, UV radiation removes about $60 \%$ of the Ag-NPs in the water, but found no effect of the UV treatment on the NPs at $\mathrm{pH}=7.5 .^{38}$ We assume that the removal efficiency of Ag-NPs by the Advanced Treatment Water Facility's UV treatment is likely to be up to $60 \%$. The corresponding removal efficiencies were not found for $\mathrm{TiO}_{2}$-NPs and $\mathrm{ZnO}-\mathrm{NPs}$.

3.2.7 Surface water. The effluent from the WWTPs in Berlin is discharged to the surrounding rivers and lakes. Here, the NPs are either transported away from the city or transported through the soil down to the groundwater at the sites where bank filtration and artificial recharge are situated.
The effluent from the Advanced Water Treatment Facility in Orange County is pumped to the Kraemer, Miller, and Miraloma Basins or to the Talbert Seawater Intrusion Barrier at the coast. At the Kraemer, Miller, and Miraloma Basins, the treated water percolates into the groundwater while the treated water directed to the intrusion barrier is pumped into the groundwater reservoir. In both cases, the water is mixed with the existing groundwater. Due to the assumed short residence time in the basins, no interactions or transformation of NPs are expected.

Several studies have been made on the fate and transformation of Ag-NPs in surface waters. The potential retention of Ag-NPs in surface water has been predicted by Monte Carlo simulations to be around $50 \% .^{17,19}$ The possible retention of $\mathrm{TiO}_{2}$-NPs and $\mathrm{ZnO}-\mathrm{NPs}$ in surface water has been assessed by experimental results and Monte Carlo simulations which estimate that $53-100 \%$ of $\mathrm{TiO}_{2}$-NPs are likely to be retained while $24-75 \%$ of $\mathrm{ZnO}-\mathrm{NPs}$ will be removed. ${ }^{17,19,42,43}$ The retention of $\mathrm{Ag}$-NPs, $\mathrm{TiO}_{2}$-NPs, and $\mathrm{ZnO}-\mathrm{NPs}$ in surface water is likely to be determined by several factors such as the surface coating of the NPs, flow rate, and $\mathrm{pH}^{.17,19,42,43}$ The found percentage ranges for retention are estimated to be the best guess for Berlin while no retention is assumed for the basins in Orange County.

3.2.8 Soil and groundwater. The unsaturated layers in Berlin and Orange County are predominantly sand and gravel, especially in the top layers. ${ }^{10,12,44}$ However, silts and clays are also present in large quantities in certain areas of Orange County. The proportion mechanisms of the sand, silt, and clay and particle route in the Santa Ana groundwater basin in Orange County are unknown. The removal efficiencies by the unsaturated zone in both cases are estimated to be $26-71 \%$ for $\mathrm{Ag}$-NPs and $5-99 \%$ for $\mathrm{TiO}_{2}$-NPs. ${ }^{45-47}$ Based on laboratory tests, the retention in the natural aquifers is expected to be governed by ionic strength, NOM, residual chloride, low grain sizes, and $\mathrm{pH}^{43,45-48}$ Based on the results produced by Keller et al., it is estimated that $72.7 \%$ of $\mathrm{TiO}_{2}-\mathrm{NPs}$ and $21.5 \%$ of ZnO-NPs will sediment in groundwater media. ${ }^{43}$ However, no studies were found on the potential effect of the interaction between groundwater and soil which could provide a different removal efficiency altogether. Nonetheless, it is assumed that sedimentation and sorption in soil is likely to act as another barrier for the transport of NPs through the soil layers.

Due to the sandy soil in the two areas, ${ }^{12,49}$ the removal efficiencies for both Berlin and Orange County are estimated to be $50-71 \%$ for Ag-NPs in the unsaturated zone, $5-99 \%$ for $\mathrm{TiO}_{2}$-NPs in unsaturated soil and $72 \%$ in saturated soil layers, and about $21.5 \%$ for $\mathrm{ZnO}-\mathrm{NPs}$ in saturated soil layers. ${ }^{43,45-47}$

3.2.9 Water treatment plants. A handful of studies have investigated the possible removal of NPs by conventional drinking water treatment. Z. Li et al. observed that a sand filter retained about $40 \%$ of Ag-citrate-NPs, about $25 \%$ of ZnO-PVA-NPs, and $0 \%$ of Ag-PVP-NPs. ${ }^{50}$ However, all the uncoated NPs examined, namely, $\mathrm{TiO}_{2}$-NPs, ZnO-NPs, and $\mathrm{CeO}_{2}$-NPs, were almost $100 \%$ retained by the sand filter. Moreover, the removal efficiency of each investigated type of 
NP will most likely be constant once a given pore volume has been reached but at various $C / C_{0}$ values $(C=$ effluent concentration, $C_{0}=$ influent concentration). ${ }^{50}$ In addition, Z. Li et al. developed a model based on the experimental results for filter sand and ran simulations for two cases of NP influents: single spiked input and continuous flow input. ${ }^{50}$ The sand filter was observed to retain a large amount of the NPs in the event of a single spiked input (influent concentration of NPs of 50-500 ppm) but if a continuous flow (influent concentration of NPs of 5-50 ppm) was simulated, almost a $100 \%$ break through rate was observed. $\mathrm{Z}$. Li et al. explains this phenomenon as being caused by steric repulsion of the coated NPs. ${ }^{50}$

Abbott Chalew et al. found the average removal efficiency of Ag-NPs by traditional water treatment plants to be around 80-98\%. ${ }^{35}$ For $\mathrm{TiO}_{2}$-NPs, the average removal efficiency

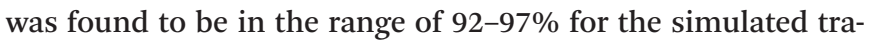
ditional water treatment, while for ZnO-NPs it was found to be $1-52 \%$. The removal efficiency of $\mathrm{ZnO}-\mathrm{NPs}$ includes zinc ions, indicating that the removal of ZnO-NPs is likely to be greater than that presented. By comparing the observed removal efficiencies by $\mathrm{Z}$. Li et al. $^{50}$ and Abbott Chalew et al. ${ }^{35}$ aeration should remove $50 \%$ or more of the NPs in the influent to the water treatment plant.

The six drinking water treatment plants in Berlin treat the extracted groundwater by conventional processes such as sand filtration, primary treatment, and secondary treatment. Li et al. found that less than $50 \%$ of the surface coated NPs will be retained by sand filters. ${ }^{50}$ As many engineered NPs are surface coated, this is likely to be the removal efficiency by sand filters in most cases. Abbott Chalew et al. found the removal efficiencies for conventional drinking water treatment processes of $\mathrm{Ag}$-NPs, $\mathrm{TiO}_{2}$-NPs, and $\mathrm{ZnO}-\mathrm{NPs}$ to be 80-98\%, 92-97\%, and $1-52 \%$, respectively. ${ }^{35}$ In Orange County, the extracted groundwater is treated by disinfection which is covered in section 3.2.6.

\subsection{Mass flow analysis}

3.3.1 Orange County. Our results show that Ag-NPs are almost completely removed $(99.97 \%)$ by the wastewater reclamation system in Orange County primarily due to the effectiveness of the processes in the conventional wastewater treatment plant and the disinfection stage in the Advanced Water Treatment Facility (Fig. 5). The worst case removal scenario predicts that about $9 \%$ of $\mathrm{TiO}_{2}$-NPs and $8 \%$ of ZnO-NPs will pass through the treatment processes and may end up in the tap water.

Fig. 6 depicts the concentrations after treatment by each treatment stage in Orange County. The estimated worst case concentration of $\mathrm{TiO}_{2}$-NPs in the influent to the WWTP is predicted to be $147 \mu \mathrm{g} \mathrm{\textrm {L } ^ { - 1 }}$ while ZnO-NPs and $\mathrm{Ag}$-NPs were predicted to be in concentrations of $280 \mathrm{ng} \mathrm{\textrm {L } ^ { - 1 }}$

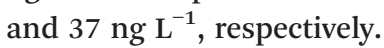

3.3.2 Berlin. The overall removal of NPs in Berlin was estimated based on the assumed removal efficiencies by the treatment stages in Table 1. The results show that the Berlin
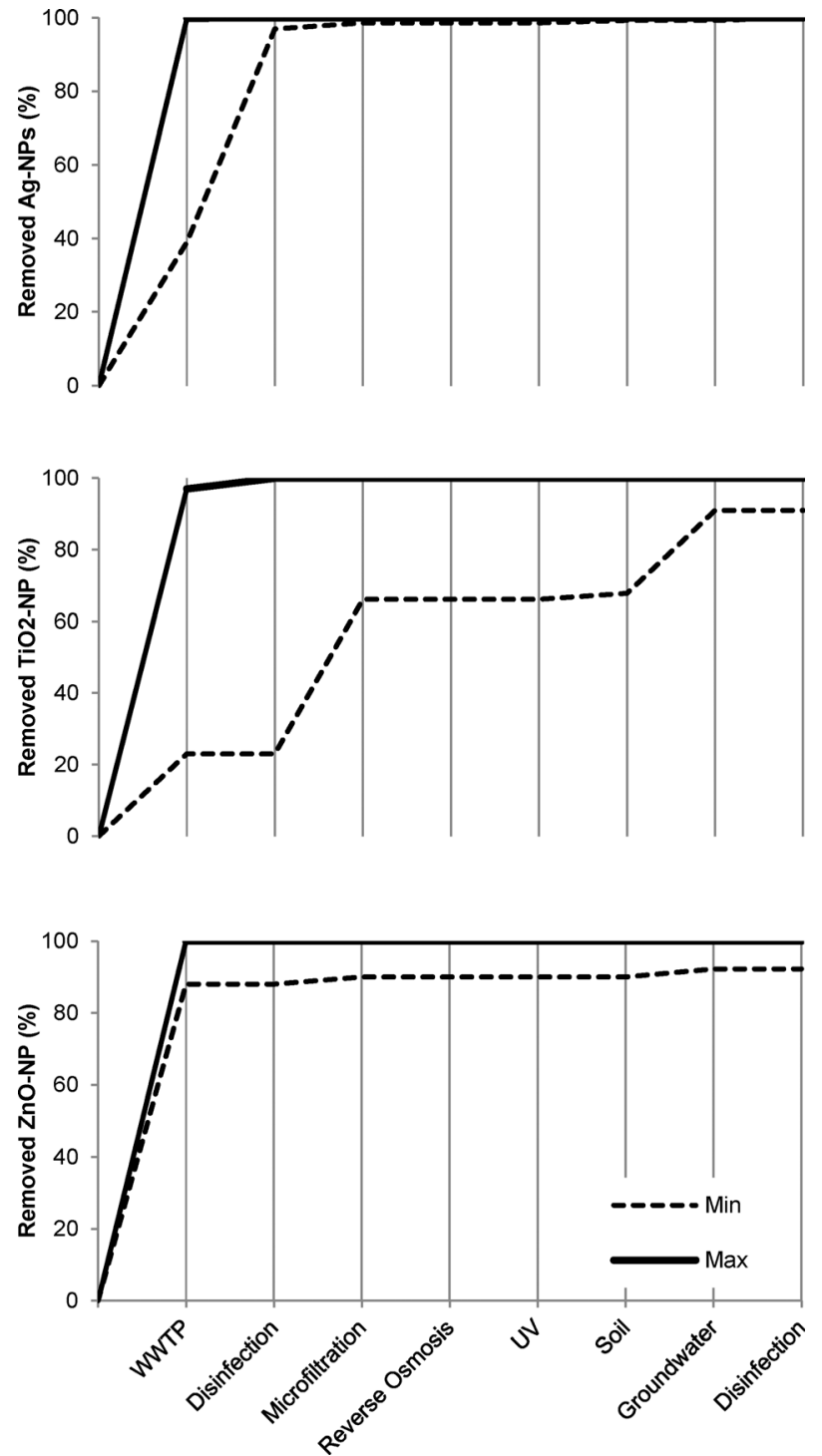

Fig. 5 Estimated accumulated percentage of removed NPs after each treatment stage in the Orange County wastewater reclamation system for the removal scenarios: minimum and maximum. When no removal efficiency has been found in the literature, it is assumed that $0 \%$ was removed for the minimum scenario and $100 \%$ removed for the maximum scenario. It is assumed that no NPs are removed in the sewers.

reclamation sequence is the most efficient in retaining $\mathrm{TiO}_{2}$-NPs. The system is also estimated to retain almost all of the Ag-NPs arriving at the WWTPs. ZnO-NPs seem to be the most difficult NP of the three to remove (Fig. 7). Especially, the usage of conventional wastewater treatment seems to be crucial in order to ensure high removal efficiency.

The estimated concentrations of the three NPs in the tap water distributed to the consumers in Berlin indicate that $\mathrm{TiO}_{2}$-NPs can be found in the largest concentrations followed by Ag-NPs. The worst case scenario predicts that all three NPs may end up in the tap water in concentrations between 0.25-13 $\mu \mathrm{g} \mathrm{L}^{-1}$ (Table 2). In addition, the system in Berlin utilizes surface water treatment plants (SWTPs) which treat the river water in order to minimize the concentration of 

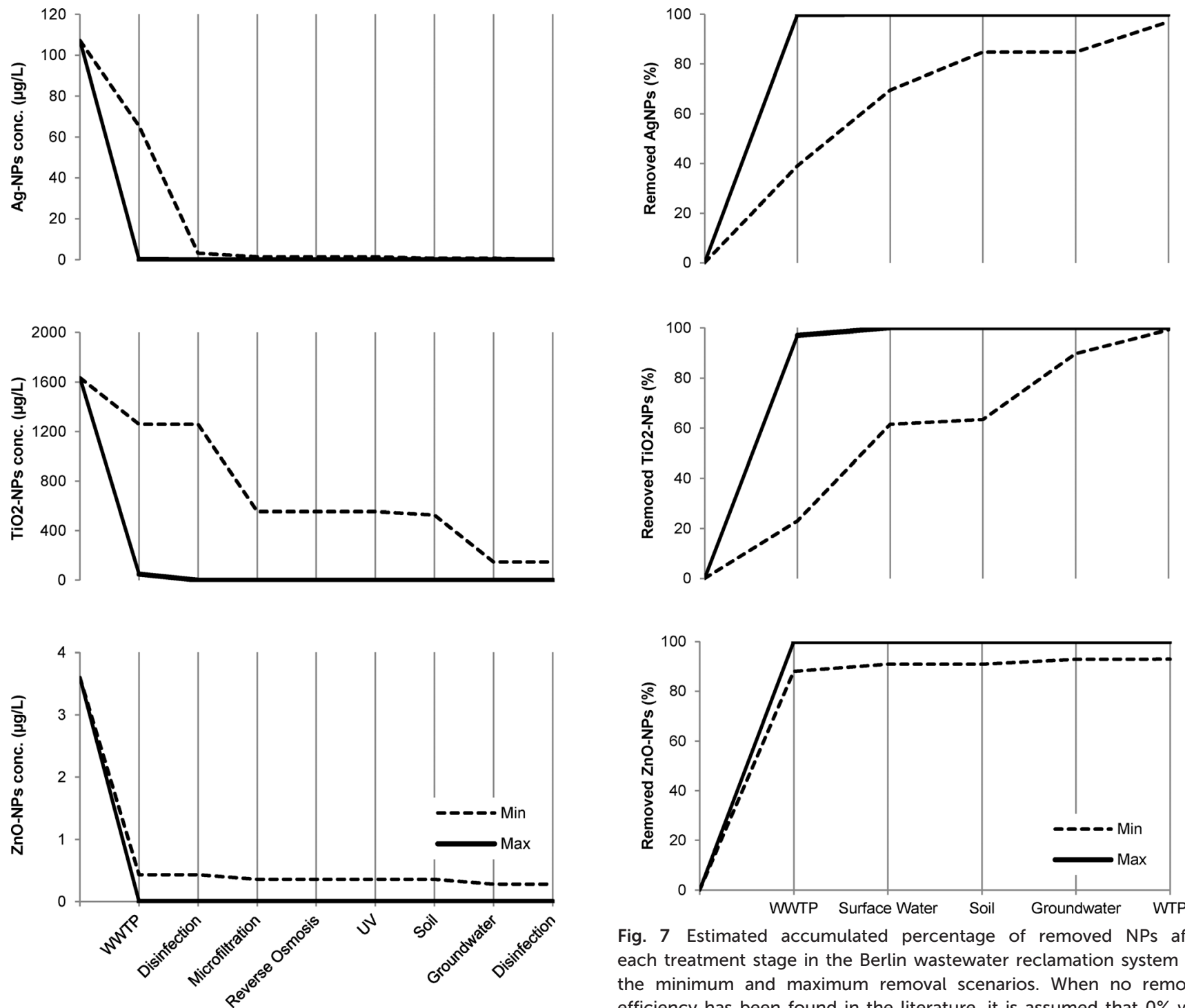

Fig. 7 Estimated accumulated percentage of removed NPs after each treatment stage in the Berlin wastewater reclamation system for the minimum and maximum removal scenarios. When no removal efficiency has been found in the literature, it is assumed that $0 \%$ was

Fig. 6 Concentration of NPs $\left(\mu \mathrm{g} \mathrm{L}^{-1}\right)$ after each treatment stage in the Orange County wastewater reclamation system for the removal scenarios: minimum and maximum. The estimated concentrations of $\mathrm{Ag}-\mathrm{NPs}$ and $\mathrm{TiO}_{2}-\mathrm{NPs}$ in the influent to the WWTP are based on the study by Tiede et al. ${ }^{8}$ while the corresponding concentration of $\mathrm{ZnO}-\mathrm{NPs}$ is based on the study by Gottschalk et al. ${ }^{17}$

phosphorus among others in the local surface water. In these plants flocculation, sedimentation, and filtration occur. ${ }^{12}$ These processes are likely to contribute to the overall NP removal efficiency by the system in Berlin. However, no information regarding the treated volume could be found. The SWTPs are therefore not included in the mass flow analyses (Fig. 8).

\section{Discussion}

\subsection{Evaluation of the wastewater reclamation systems in Orange County and Berlin}

The mass flow analyses in the previous sections of the wastewater reclamation systems in Orange County and Berlin removed for the minimum scenario and 100\% removed for the maximum scenario. It is assumed that no NPs are removed in the sewers. WTP: conventional drinking water treatment.

indicate that considering a worst case scenario, the advanced treatment currently in operation in Orange County is likely to be more efficient towards Ag-NPs than the corresponding system in Berlin while the opposite is the case for $\mathrm{TiO}_{2}-\mathrm{NPs}$ and ZnO-NPs (Table 2).

The concentration of $\mathrm{TiO}_{2}$-NPs in the tap water for the worst case scenario in Berlin is less than $10 \%$ of the corresponding concentration in Orange County. On the other hand, the system in Orange County has a worst case overall treatment efficiency of $99.97 \%$ for Ag-NPs, whereas in Berlin, the system is predicted to remove just 97\% of the Ag-NPs. For ZnO-NPs, the found concentrations in the worst case scenario are almost equivalent for both systems.

The two disinfection stages (sodium hypochlorite) in the wastewater reclamation system in Orange County are the main cause of the higher worst case removal efficiency of 
Table 2 Summary of the estimated removal efficiencies and worst case concentrations of each NP by the wastewater reclamation system in Orange County and Berlin

\begin{tabular}{lllll}
\hline & & $\mathrm{Ag}$ & $\mathrm{TiO}_{2}$ & $\mathrm{ZnO}$ \\
\hline Removal efficiency & Orange County & $99.97-100$ & $91-100$ & $92-100$ \\
range $(\%)$ & Berlin & $97-100$ & $99.2-100$ & $93-100$ \\
Worst case & Orange County & 0.04 & 147 & 0.28 \\
concentrations & Berlin & 3.3 & 13 & 0.25 \\
in tap water $\left(\mu \mathrm{g} \mathrm{L}^{-1}\right)$ & & & &
\end{tabular}

Ag-NPs compared to the system in Berlin. For Ag-NPs, the difference in the worst case removal efficiencies for the two systems is mainly a $95 \%$ removal efficiency by the two disinfection stages and 55\% removal efficiency by the microfiltration treatment in Orange County versus a $50 \%$ and $80 \%$ removal by the surface water and WTP, respectively, in the
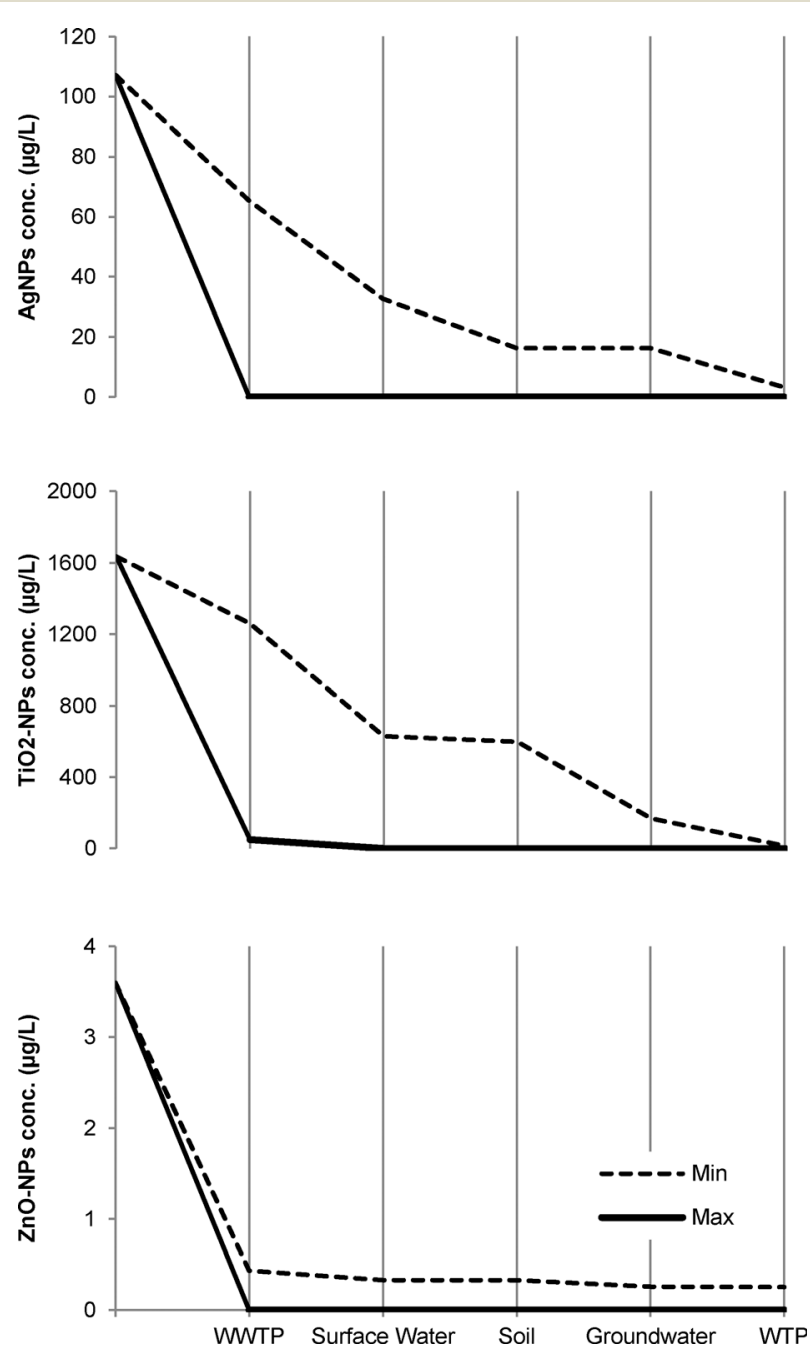

Fig. 8 Concentration of NPs ( $\mu \mathrm{g} \mathrm{L}^{-1}$ ) after each treatment stage in the Berlin wastewater reclamation system for the removal scenarios: minimum and maximum. The estimated concentrations of Ag-NPs and $\mathrm{TiO}_{2}$-NPs in the influent to the WWTP are based on the study by Tiede et al. $^{8}$ while the corresponding concentration of ZnO-NPs is based on the study by Gottschalk et al. ${ }^{17}$ WTP: conventional drinking water treatment.
Berlin system. Therefore, the combination of size exclusion by microfiltration ${ }^{35}$ and especially oxidative dissolution and aggregation of Ag-NPs by disinfectants ${ }^{38}$ seem to be a more effective barrier than the combination of surface water (aggregation) and drinking water treatment plants (coagulation and bioadsorption) in Berlin. ${ }^{35,42,43,50,51}$

The primary reason for the difference in the worst case removal efficiency of $\mathrm{TiO}_{2}$-NPs by the two wastewater reclamation systems is the process in surface waters and water treatment plants in Berlin. The found worst case removal efficiencies of $\mathrm{TiO}_{2}$-NPs by the advanced treatment in Orange County are down to the lower minimum removal efficiency by microfiltration. The different removal mechanisms provide the system in Berlin with an advantage as no removal efficiency of $\mathrm{TiO}_{2}$-NPs by disinfection, reverse osmosis, or UV could be identified. The differences between the microfiltration treatment used in Orange County and the processes occurring in water treatment plants and rivers are predominantly due to the removal mechanism in microfiltration being reliant on size exclusion, ${ }^{35}$ while the natural attraction of $\mathrm{TiO}_{2}$-NPs to the particles and matter in surface water (including mutual attraction between the $\left.\mathrm{TiO}_{2}-\mathrm{NPs}\right)^{42,43,51}$ as well as the coagulation ${ }^{35}$ and bioadsorption ${ }^{50}$ in conventional water treatment are observed to be more effective.

The difference between the found worst case removal efficiencies of ZnO-NPs for Berlin and Orange County is the smallest compared to those corresponding for Ag-NPs and $\mathrm{TiO}_{2}$-NPs. However, the WWRS in Berlin is still predicted to be slightly more effective than the corresponding system in Orange County due to the slightly higher overall estimated worst case removal efficiency of ZnO-NPs by surface waters and WTPs than the corresponding efficiency by microfiltration.

\subsection{The known barriers against NPs}

The literature search results indicate that ultrafiltration provides the best removal efficiency of Ag-NPs (98-100\% removed) due to size exclusion. ${ }^{35}$ Moreover, the heteroaggregation occurring in treatment processes in WWTPs and drinking water treatment plants is likely to provide a significant retention of Ag-NPs. The dominant removal mechanism in WWTPs suggested by the identified studies is the natural attraction of $\mathrm{Ag}$-NPs to the total suspended solids in the medium and the bacteria in the activated sludge. ${ }^{20,30}$ Disinfection and microfiltration are also likely to retain a large ratio of Ag-NPs. UV disinfection was effective predominantly due to the dissolution and aggregation of Ag-NPs. ${ }^{38}$

By similar comparison, ultrafiltration is likely to be the most efficient barrier against $\mathrm{TiO}_{2}$-NPs (96-100\% removed) due to size exclusion. ${ }^{35}$ However, the coagulation, sedimentation, and flocculation in the water treatment result in a high removal efficiency of $\mathrm{TiO}_{2}$-NPs (92-97\%). Furthermore, high single removal efficiencies of $\mathrm{TiO}_{2}$-NPs were documented for WWTPs, surface waters, soil, and microfiltration, in which the highest estimated removal efficiencies of $\mathrm{TiO}_{2}$-NPs were found to be $97 \%, 99.9 \%, 99 \%$, and $100 \%$, respectively. The 
aggregation and biosorption of $\mathrm{TiO}_{2}$-NPs in WWTPs were observed to be the primary removal mechanisms. ${ }^{24,27}$ The removal efficiency of $\mathrm{TiO}_{2}$-NPs by (sandy) soil was very much dependent on the $\mathrm{pH}$ value of the soil which could lead to an almost negligible removal efficiency (5\%). Moreover, if the soil has a high dissolved organic carbon content, a high removal efficiency ( $>95 \%)$ can be expected due to the composition of the clay. The size exclusion of the aggregated $\mathrm{TiO}_{2}$-NPs due to the pore size of the microfiltration membrane was the main reason for the high removal efficiency. ${ }^{35}$ In surface waters with acidic conditions and low flow rate $\left(3.2 \mathrm{~L} \mathrm{~s}^{-1}\right)$, the sedimentation of $\mathrm{TiO}_{2}$-NPs is found to be almost $100 \%$ regardless of surface coating. However, by increasing the $\mathrm{pH}$ and flow rate, the $\mathrm{TiO}_{2}$-NPs are more difficult to settle. ${ }^{42}$

The processes in the WWTP are likely to be the most efficient barrier against the break through of ZnO-NPs. Hou et al. found that about $70 \%$ of ZnO-NPs (no surface coating) are likely to rapidly settle in the primary clarification tank and the remaining ZnO-NPs are suggested to be completely removed by processes in the aeration and activated sludge treatment stages. $^{28}$ The primary removal mechanism was found to be biosorption. Rapid settling is also observed in surface water media in which 8 hours of flocculation and 1 hour of sedimentation of ZnO-NPs are likely to result in $75 \%$ removal of ZnO-NPs. ${ }^{51}$ However, a removal efficiency of ZnO-NPs of $24 \%$ in river water media indicates that the flow rate is the primary parameter for the removal of ZnO-NPs in surface water. $^{43}$ Ultrafiltration and microfiltration can also exhibit high removal efficiencies of ZnO-NPs (98\% and 64\%, respectively) but due to the dissolution of ZnO-NPs into zinc ions, these barriers are also observed to exhibit very low removal efficiencies (17\% and $4 \%$, respectively). ${ }^{35}$

In general, the identified studies highlight aggregation especially heteroaggregation - and size exclusion as essential removal mechanisms in wastewater and water treatments. ${ }^{20,52}$

\subsection{Knowledge gaps}

In our attempt to complete a mass flow analysis for potable water reclamation in Orange County and Berlin, a marked lack of observations from several treatment stages and compartments is evident. This prevents an accurate estimation of the fate of the investigated NPs. Of the three NPs in question, ZnO-NPs have received the least attention. Only single observations were found for several combinations of NP types and treatment stages, for example ZnO-NPs in WWTP and groundwater (Table 1). The ranges of the removal efficiencies of $\mathrm{Ag}$-NPs and $\mathrm{TiO}_{2}$-NPs were found for wastewater treatment, microfiltration, and soil layers whereas only single observations for the removal efficiencies of Ag-NPs and $\mathrm{TiO}_{2}-\mathrm{NPs}$ could be found for disinfection and groundwater, respectively.

No studies which examined the removal efficiency of the NPs by reverse osmosis were identified. The pore size of the reverse osmosis membranes is below $0.1 \mathrm{~nm}$ and it is justified to assume that the reverse osmosis membranes will have a removal efficiency at least equal to the ultrafiltration membranes or better. But as Bellona et $a l^{40}$ have found, rejection at the membrane might not be straightforward, because the size exclusion of the compounds may not be the only parameter controlling rejection. In addition, primarily due to their tendency to dissolve into zinc ions, ZnO-NPs have been observed to be difficult to remove by size exclu$\operatorname{sion}^{35}$ and further studies are needed in order to determine the exact concentrations of $\mathrm{ZnO}$-NPs which are able to break through the barriers in a given system. In the review of the identified studies, the WWTPs were found to exhibit the highest removal efficiency of ZnO-NPs. Moreover, WWTPs are also likely to exhibit relatively high removal efficiencies of $\mathrm{Ag}$-NPs and $\mathrm{TiO}_{2}$-NPs which indicate that the biological processes in the WWTPs at the current knowledge level appear as the most efficient NP barriers in wastewater reclamation systems.

In general, further studies are needed in order to attain more knowledge on the fate of NPs in the various treatment stages. Only the studies on the removal efficiencies of the three NPs by WWTPs and surface waters can be regarded to provide a minimum level of nuanced understanding on the fate and behavior of the NPs. This indicates that the primary focus of the research community has been on the release to and fate in the environment and to a lesser extent the risk of exposure to humans through drinking water. Therefore, there is a lack of knowledge on the removal efficiency of more advanced treatment processes, with no observations reported for reverse osmosis. Furthermore, the studies evaluated in this study have primarily been conducted in laboratory settings or by modelling and simulation, which might provide a distorted perception of the transformation of NPs in real environments which is also highlighted in the work of Garner and Keller. ${ }^{52}$

Finally, an important knowledge gap lies in the estimation of the influent concentration. The influent concentrations of each NP in the mass flow analyses are based on the results found by Tiede et al. ${ }^{8}$ and Gottschalk et al. ${ }^{17}$ and are based primarily on the observed behavior of the NPs in the various treatment processes and previous results from similar studies as well as assumptions on the production volume and WWTP influent concentration of the NPs. Although, we do believe that these concentrations represent the best known emission concentrations of the NPs, it should be acknowledged that different estimations are available and that influent and effluent estimations will of course depend on fundamental assumptions about, for instance, production volumes. ${ }^{53}$

\section{Conclusions}

Based on a mass flow analysis of possible nanoparticle fate and treatment in two typical potable reuse systems, we have found that:

- Considering a worst case scenario, nanoparticles may reach the drinking water supply in $n g \mathrm{~L}^{-1}$ to $\mu \mathrm{g} \mathrm{L}^{-1}$ concentrations 
after both advanced membrane-based reclamation and simpler conventional water treatment have been employed.

-There are marked knowledge gaps and actual removal efficiencies by several combinations of nanoparticle and treatment stages are largely unknown.

- Observations reported so far support biological treatment processes as the most efficient engineered barriers against nanoparticles in wastewater reclamation systems for potable reuse.

Whether the estimated concentrations pose a risk to humans is yet to be determined.

\section{References}

1 M. Rygaard, P. J. Binning and H.-J. Albrechtsen, J. Environ. Manage., 2011, 92, 185-194.

2 D. Gerrity, B. Pecson, R. S. Trussell and R. R. Trussell, J. Water Supply: Res. Technol.-AQUA, 2013, 62, 321.

3 H. L. Leverenz, G. Tchobanoglous and T. Asano, J. Water Reuse Desalin., 2011, 1, 2.

4 Nanodb.dk, 2014.

5 Nanotechproject.org, 2014.

6 European Commission, Types and Uses of Nanomaterials, including Safety Aspects, 2012.

7 F. Gottschalk, R. W. Scholz and B. Nowack, Environ. Model. Softw., 2010, 25, 320-332.

8 K. Tiede, P. K. Westerhoff, S. Foss Hansen, G. Fern, R. J. Aitken, Q. Chaudhry and A. B. A. Boxall, Review of the risks posed to drinking water by man-made nanoparticles, 2011.

9 MWDOC, 2010.

10 GWRS, Technical Brochure, 2013.

11 Veolia Water, Information Sheets Regarding Water Recycling, 2005.

12 Berliner Wasserbetriebe, Water for Berlin, 2013.

13 G. Massmann, J. Sultenfuss, U. Dunnbier, A. Knappe, T. Taute and A. Pekdeger, Hydrol. Processes, 2008, 22, 788-801.

14 T. Heberer, J. Hydrol., 2002, 266, 175-189.

15 P. Weyrauch, A. Matzinger, E. Pawlowsky-Reusing, S. Plume, D. von Seggern, B. Heinzmann, K. Schroeder and P. Rouault, Water Res., 2010, 44, 4451-4462.

16 P. H. Brunner and H. Rechberger, Practical handbook of material flow analysis : Advanced methods in resource and waste management, Lewis Publishers, 2004.

17 F. Gottschalk, T. Sonderer, R. W. Scholz and B. Nowack, Modeled environmental concentrations of engineered nanomaterials ( $\mathrm{TiO}_{2}, \mathrm{ZnO}, \mathrm{Ag}$, CNT, fullerenes) for different regions, Environ. Sci. Technol., 2009, 43, 9216-9222.

18 A. B. A. Boxall, Q. Chaudhry, C. Sinclair, A. Jones, R. J. Aitken, B. Jefferson and C. Watts, Current and Future Predicted Environmental Exposure to Engineered Nanoparticles, 2007.

19 N. C. Mueller and B. Nowack, Environ. Sci. Technol., 2008, 42, 4447-4453.

20 R. Kaegi, A. Voegelin, C. Ort, B. Sinnet, B. Thalmann, J. Krismer, H. Hagendorfer, M. Elumelu and E. Mueller, Water Res., 2013, 47, 3866-3877.

21 E. Jeong, S. R. Chae, S. T. Kang and H. S. Shin, Water Sci. Technol., 2012, 65, 1298-1303.
22 R. Kaegi, A. Voegelin, B. Sinnet, S. Zuleeg, H. Hagendorfer, M. Burkhardt and H. Siegrist, Environ. Sci. Technol., 2011, 45, 3902-3908.

23 L. Li, G. Hartmann, M. Döblinger and M. Schuster, Quantification of Nanoscale Silver Particles Removal and Release from Municipal Wastewater Treatment Plants in Germany, Environ. Sci. Technol., 2013, 13, 7317-7323.

24 Y. Wang, P. Westerhoff and K. D. Hristovski, J. Hazard. Mater., 2012, 201-202, 16-22.

25 N. Musee, J. N. Zvimba, L. M. Schaefer, N. Nota, L. M. Sikhwivhilu and M. Thwala, J. Environ. Sci. Health, Part A: Toxic/Hazard. Subst. Environ. Eng., 2014, 49, 59-66.

26 A. C. Johnson, M. J. Bowes, A. Crossley, H. P. Jarvie, K. Jurkschat, M. D. Jürgens, A. J. Lawlor, B. Park, P. Rowland, D. Spurgeon, C. Svendsen, I. P. Thompson, R. J. Barnes, R. J. Williams and N. Xu, Sci. Total Environ., 2011, 409, 2503-2510.

27 M. A. Kiser, H. Ryu, H. Jang, K. Hristovski and P. Westerhoff, Water Res., 2010, 44, 4105-4114.

28 L. Hou, J. Xia, K. Li, J. Chen, X. Wu and X. Li, Water Sci. Technol., 2013, 67, 254-260.

29 L. K. Limbach, R. Bereiter, E. Müller, R. Krebs, R. Galli and W. J. Stark, Environ. Sci. Technol., 2008, 42, 5828-5833.

30 S. P. Dhas, P. J. Shiny, S. Khan, A. Mukherjee and N. Chandrasekaran, J. Basic Microbiol., 2013, 1-12.

31 S. Eduok, B. Martin, R. Villa, A. Nocker, B. Jefferson and F. Coulon, Ecotoxicol. Environ. Saf., 2013, 95, 1-9.

32 G. Liu, D. Wang, J. Wang and C. Mendoza, Sci. Total Environ., 2011, 409, 2852-2857.

33 X. Sun, Z. Sheng and Y. Liu, Sci. Total Environ., 2013, 443, 828-835.

34 X. Zheng, R. Wu and Y. Chen, Environ. Sci. Technol., 2011, 45, 2826-2832.

35 T. E. Abbott Chalew, G. S. Ajmani, H. Huang and K. J. Schwab, Environ. Health Perspect., 2013, 121, 1161-1166.

36 D. A. Ladner, M. Steele, A. Weir, K. Hristovski and P. Westerhoff, J. Hazard. Mater., 2012, 211-212, 288-295.

37 R. W. Baker, Membrane Technology and Applications, John Wiley \& Sons, Ltd, Chichester, UK, 2012.

38 Z. Yuan, Y. Chen, T. Li and C.-P. Yu, Chemosphere, 2013, 93, 619-625.

39 City of Huntington Beach, 2010 Urban Water Management Plan, 2011.

40 C. Bellona, J. E. Drewes, P. Xu and G. Amy, Water Res., 2004, 38, 2795-2809.

41 P. Xu, J. E. Drewes, T.-U. Kim, C. Bellona and G. Amy, J. Membr. Sci., 2006, 279, 165-175.

42 N. Ticiana Boncagni, J. M. Otaegui, E. Warner, T. Curran, J. Ren and M. Marta Fidalgo de Cortalezzi, Exchange of $\mathrm{TiO}_{2}$ Nanoparticles between Streams and Streambeds, Environ. Sci. Technol., 2009, 7699-7705.

43 A. A. Keller, H. Wang, D. Zhou, H. S. Lenihan, G. Cherr, B. J. Cardinale, R. Miller and Z. Ji, Environ. Sci. Technol., 2010, 44, 1962-1967.

44 MWDSC, Final Groundwater Assessment Study, 2007. 
45 O. Sagee, I. Dror and B. Berkowitz, Chemosphere, 2012, 88, 670-675.

46 N. Solovitch, J. Labille, J. Rose, P. Chaurand, D. Borschneck, M. R. Wiesner and J.-Y. Bottero, Environ. Sci. Technol., 2010, 44, 4897-4902.

47 J. Fang, X. Shan, B. Wen, J. Lin and G. Owens, Environ. Pollut., 2009, 157, 1101-1109.

48 S. Bae, Y. S. Hwang, Y.-J. Lee and S.-K. Lee, Environ. Health Toxicol., 2013, 28, e2013006.

49 OCWD, 2010.
50 Z. Li, A. Aly Hassan, E. Sahle-Demessie and G. A. Sorial, Water Res., 2013, 47, 6457-6466.

51 Y. Zhang, Y. Chen, P. Westerhoff, K. Hristovski and J. C. Crittenden, Water Res., 2008, 42, 2204-2212.

52 K. L. Garner and A. A. Keller, J. Nanopart. Res., 2014, 16, 2503.

53 A. A. Keller, S. McFerran, A. Lazareva and S. Suh, J. Nanoparticle, 2013, 15, 1692.

54 G. Tchobanoglous, H. Leverenz, M. H. Nellor and J. Crook, Direct potable reuse. A path forward, 2011. 